\title{
Chapter 12 \\ Optimal Energy Portfolios in the Heating Sector and Flexibility Potentials of Combined-Heat-Power Plants and District Heating Systems
}

\section{Maciej Raczyński, Artur Wyrwa, Marcin Pluta, and Wojciech Suwała}

\begin{abstract}
This chapter examines the role of centralized district heating (DH) systems in context of energy system flexibility and decarbonization. The analysis is performed by applying the model TIMES-Heat-EU. Capacity expansion and operation of the district heating generation units is mainly driven by the evolution of the district heating demand, which varies between the REFLEX scenarios. In all scenarios fuel and technology switches toward bioenergy and natural gas leading to $\mathrm{CO}_{2}$ emission reduction. Since the total amount of energy produced (both heat and electricity) is the highest in the High-RES centralized scenario, the corresponding $\mathrm{CO}_{2}$ emissions for district heating are the highest as well. The $\mathrm{CO}_{2}$ emissions can be reduced by $\sim 60 \%$ in 2050 compared to 2015 . Furthermore, the role of thermal energy storage and power-to-heat technologies is examined.
\end{abstract}

\subsection{Introduction}

At present about half of the final energy consumption in the EU is associated with heating and cooling purposes (European Commission 2016). These energy services are also expected to have a significant share in future energy consumption. In many EU countries, in particular in Scandinavia, Central, and Eastern Europe, a significant proportion of the heat demand in high-density urban areas is covered by district heating networks in which pressurized hot water is used as heat carrier at temperatures below $100^{\circ} \mathrm{C}$ (Lund et al. 2014). District heating (DH) has the benefits of integrating local heat resources, including waste heat and renewables, and of improved emission control (especially local). Supplying the heat produced in combined heat and power plants (CHPs) not only generates higher overall efficiency but also increases the flexibility of local power systems. Initiatives, such as "District Heat Atlas" (Möller et al. 2018) or "Urban Heat Demand Map" (Wyrwa and Chen 2017) are useful for the

M. Raczyński · A. Wyrwa $(\bowtie) \cdot$ M. Pluta $\cdot$ W. Suwała

AGH University of Science and Technology, Cracow, Poland

M. Raczyński

e-mail: awyrwa@agh.edu.pl 
development of heat supply strategies and plans for different spatial scales such as national, regional, or local. District heating development requires high initial investments, and its economic feasibility is often constrained by the size of the local market. Therefore, various support mechanisms have been implemented by the EU member states to promote district heating and the development of cogeneration, including tax advantages, feed-in-tariffs, certificates, grants, and other kinds of additional support. For instance, Moya (2013) analyzes how to incentivize the growth of CHPs capacities, how to create attractive economic conditions for investors, as well as how to overcome existing barriers, e.g., complexity of the law. Although, there is no clear evidence that the countries which have applied CHP dedicated support mechanisms have been more effective in promoting the development of cogeneration than other countries, the results show that countries where cogeneration plays a significant role are sensitive to the presence of support mechanisms. The analysis carried out in Moya (2013) shows that none of the identified barriers is decisive in preventing the development of cogeneration. The obtained results also indicate that the possible overlap between RES and CHP support programs does not significantly affect the promotion of the CHP development. The report published by Cogen Europe (2011) underlines that the objective of ensuring high efficiency and sustainable development of the European energy system can be achieved through, inter alia, the increased use of cogeneration and RES. It is pointed out that the key elements are-firstly, the transition from fossil fuels to RES in electricity and heat production and secondly, the increase in energy efficiency, e.g., through the development of cogeneration. Still in the 2000s district heating has been produced in large extent based on fossil fuels such as gas, coal, or oil. Regardless, the transformation toward a low-carbon (or even carbon-free) district heating systems has already begun and district heating systems are in the focus of a sustainable energy system. Such transformation is possible by enabling a technology switch from fossil fuel to RES (e.g., Sweden is the world bioenergy leader as bioenergy accounts for $33 \%$ of the national final energy consumption, cf. World Energy Council (2016)), but also requires further integration of district heating systems into the power system to enlarge district heating flexibility.

Different modeling studies have been performed to analyze potential pathways for future development of the district heating sector. For instance, in Connolly et al. (2014) a methodology based on the combination of geographical information systems (GIS) and the energy system model EnergyPLAN is applied to determine the potential for heat networks and to elaborate plausible district heating development scenarios that would help to further decarbonize the EU energy system. In this chapter the TIMES-Heat-EU model is applied to explore the development of the district heating generation mix for the EU member states in the REFLEX scenarios (cf. Chapter 2).

\subsection{TIMES-Heat-EU Model}

TIMES-Heat-EU model has been developed to assess the transition pathways toward more sustainable district heating supply and to analyze the role of district heating 
systems in context of energy system flexibility. The model was formulated with the help of the TIMES generator (Loulou 2008) and belongs to the class of integrated capacity expansion and dispatch planning models. TIMES-Heat-EU is dedicated to model the centralized heat supply by heat-only plants (HOPs) as well as combined heat and power plants (CHPs). The district heating demand is divided into three end-use sectors: the residential, tertiary, and industry sector.

The model uses a bottom-up approach, in which CHPs and HOPs are aggregated into main types according to the fuel used and type of installed turbine (cf. Fig. 12.1). The model considers main types of thermal energy storage (TES) in a short-term and seasonal perspective. The application of thermal energy storage enables the decoupling from power generation and heat generation. The operation of CHPs is influenced by electricity price signals. Power-to-heat $(\mathrm{PtH})$ technologies, such as large electric heaters and heat pumps, can use electricity that would be otherwise curtailed (e.g., RES surpluses). The geographical coverage of the model considers the member states of the EU-27 and the United Kingdom. The time horizon covers the time period from 2015 to 2050 with five years' time steps. Each modeling year is further divided into 224 time-slices derived by aggregating the data every three hours in seven days for four seasons $(8 \times 7 \times 4)$. The model is calibrated for 2015 based on the EUROSTAT data (Eurostat 2017a; Eurostat 2017b; Eurostat 2017c).

TIMES-Heat-EU solves the linear programming problem of district heating supply. District heat producers, represented by heat-only-plants, CHPs, and PtH, are maximizing their surplus. The optimization is constrained by a set of equation and inequalities. The main equations include: (i) commodity balance equations e.g., for district heating and electricity, (ii) $\mathrm{CHP}$ annual overall efficiency requirements

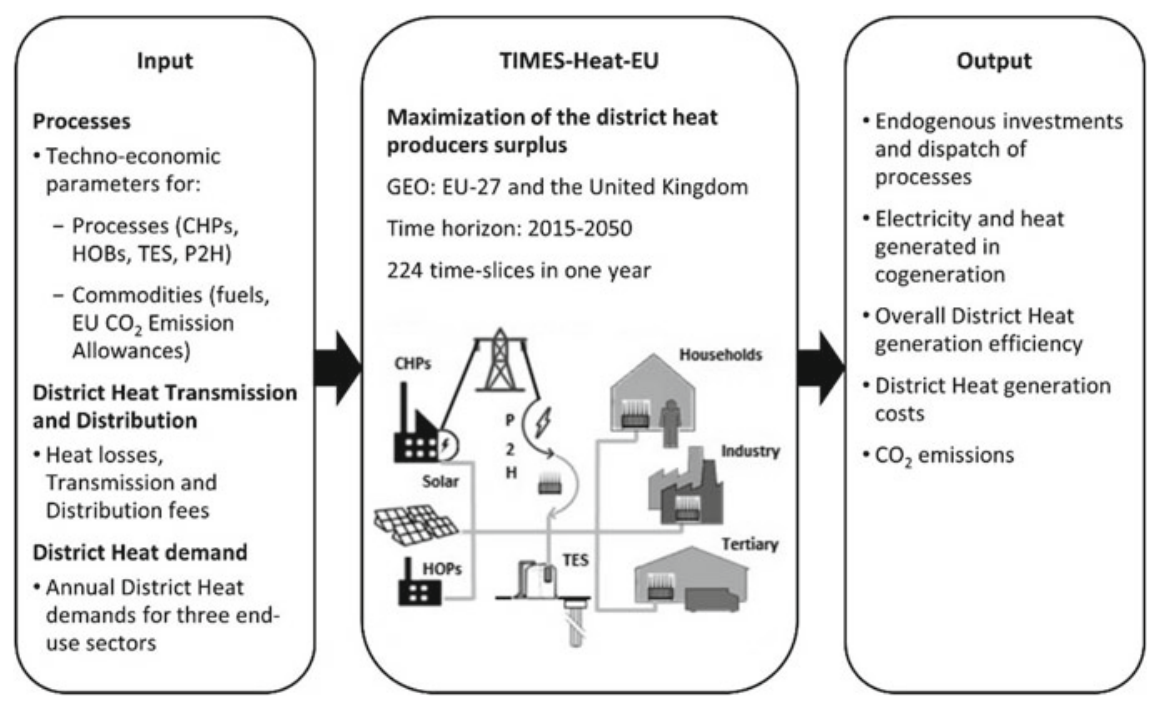

Fig. 12.1 Schematic illustration of the district heating supply model-TIMES-Heat-EU (Source Own illustration) 
in compliance with the EU legislation, (iii) required share of electricity generated in highly efficient cogeneration, (iv) ramping constraints for the operation of units.

The main output is the mix of heat generating technologies and their dispatch as well as the district heating prices. For a given country the district heating price is calculated as the weighted average (by heat production level) of district heating generation costs of individual CHPs and heat-only-plants including costs of purchasing $\mathrm{CO}_{2}$ allowances under consideration of the EU ETS. The results of TIMES-Heat-EU underline the economic feasibility of more flexible and RES-oriented cogeneration.

\subsection{Developments in the District Heating Sector}

One of the most important input parameters influencing the development of district heating systems is the change in the future district heating demand, which is exogenous input parameter for TIMES-Heat-EU provided by the FORECAST model (cf. Chapters 3, Chapter 6 and 7).

As illustrated in Fig. 12.2, the demand for district heating in 2050 is expected to be lower than today in the Mod-RES and High-RES decentralized scenario, mainly due to progressive implementation of low-energy and refurbished buildings. The more significant drop in the High-RES decentralized scenario is due to the fact that, on top of that, central heating systems play a more important role in this scenario. Only the High-RES centralized scenario assumes an increase in the future DH demand mainly because of supporting measures introduced in this scenario in the FORECAST model, such as reinforcing district heating network to realize a more viable heating infrastructure (cf. Chapter 6).

The additional constraint considered in TIMES-Heat-EU is that in the Mod-RES and High-RES centralized scenarios the overall EU-wide relative share of electricity

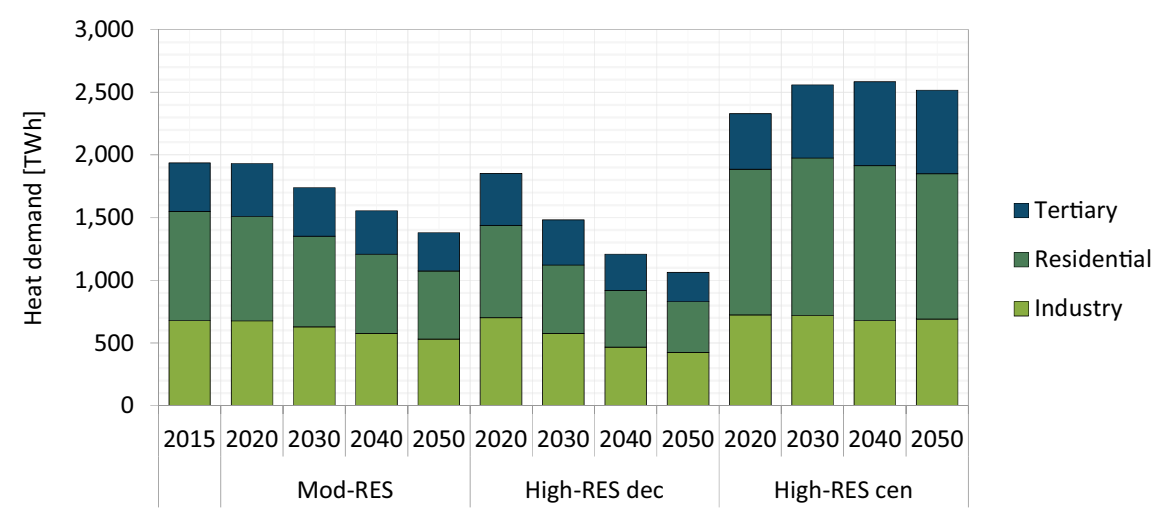

Fig. 12.2 Development of district heating demand in REFLEX scenarios across all modeled countries (Source Data according to model results from FORECAST) 
produced in cogeneration will be the same as today, i.e., approximately $12 \%$. This assumption is in line with the results of the EU28 Reference Scenario 2016 (cf Capros et al. 2016) derived by applying the PRIMES model. Such constraint is not imposed in the High-RES decentralized scenario due to infeasibility of the solution. ${ }^{1}$

Others factors influencing the model results are: prices of $\mathrm{CO}_{2}$ emission allowances, techno-economic parameters of processes employed in DH systems as well as potentials and costs of fuel and energy carriers. The coupling of the power and heat sectors is introduced by enabling CHPs having income from both, heat as well as electricity sales. At the same time, the application of power-to-heat technologies requires on the one hand, purchased electricity from the market and, on the other, generates income from heat sales. The income from heat sales is based on the average annual DH price calculated by TIMES-Heat-EU, whereas the income from electricity sales is based on the wholesale electricity prices calculated by ELTRAMOD (cf. Chapters 3 and 10). Thus, the price signals on the wholesale market derived in an iterative model coupling process with ELTRAMOD play a crucial role not only for dispatch decisions regarding CHPs, heat storage systems, and power-to-heat technologies, but also for investment decisions regarding new generation capacities. Moreover, the obtained results consider competition between existing actors (DH generation technologies), which is not always straightforward. For instance, reacting to the low electricity prices during some periods (time-slices), power-to-heat technologies have an incentive to produce district heating and thus rise the residual load contributing to upward flexibility (i.e., increasing electricity demand). However, with limited overall district heating demand, this heat could not be any longer produced in CHPs and thus is a lost opportunity to gain income from district heating and electricity sales. It has also consequences on the general activity of CHPs due to the efficiency requirements imposed on electricity from CHPs. As stated by the Directive 2012/27/EU electricity is considered as produced in high efficiency cogeneration only if the total annual efficiency of the unit is greater than 75 or $80 \%$ (depending on the technology employed).

\subsubsection{Scenario Results}

Figure 12.3 depicts the development of electricity generating capacities of CHPs in the different REFLEX scenarios. In general, a switch toward natural gas and bioenergy-fueled plants can be observed. In the Mod-RES scenario some coal-fired capacities exist, but these are plants that are decommissioned and thus ending their operation in 2045 (cf. fuel input in Fig. 12.8).

\footnotetext{
${ }^{1}$ TIMES-Heat-EU contains a constraint to enforce new CHP plants to work as high-efficiency cogeneration units. This means that the ratio of energy output (heat and electricity) to fuel input has to be greater than the given efficiency threshold (e.g., $80 \%$ for CCGT). This efficiency requirement cannot be achieved with low DH demand while enforcing CHP plants to have a $12 \%$ share in total electricity generation - as it is in High-RES decentralized scenario (cf. Fig. 12.2). The actual shares of electricity generated by CHP units for each scenario are given in Table 12.1.
} 


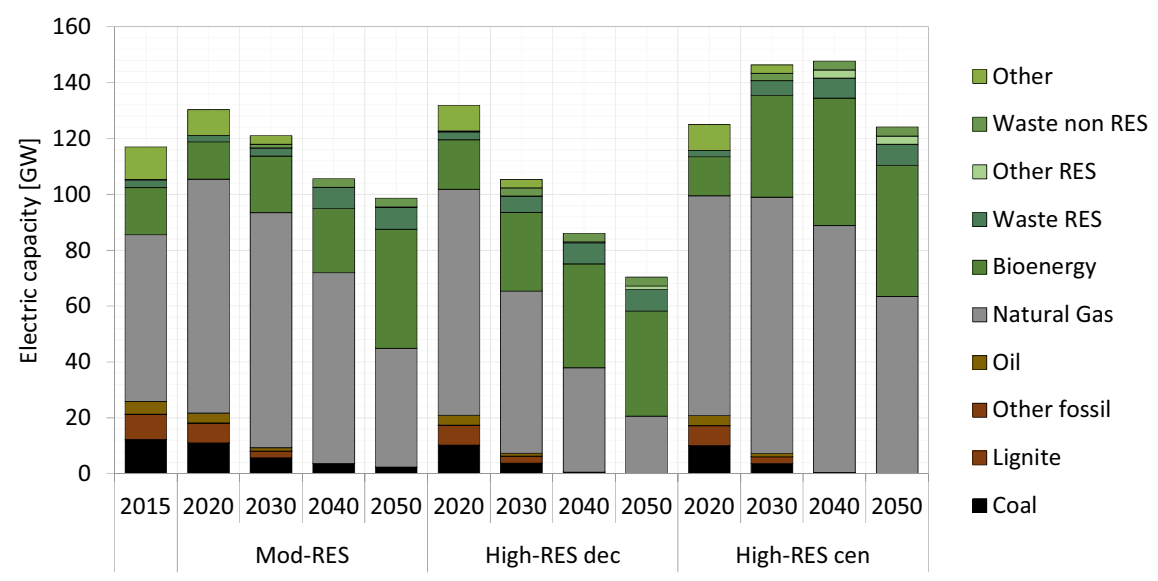

Fig. 12.3 Overall electric capacity of CHP plants in the REFLEX scenarios across all modeled countries (Source Data according to TIMES-Heat-EU model results)

In the case of the High-RES scenarios, due to increasing $\mathrm{CO}_{2}$ prices no other fossil fuels than natural gas-fired power plants are installed from 2030 onwards. The capacity expansion of CHPs is mainly driven by the evolution of the district heating demand. That is why the highest capacity expansion can be observed in the High-RES centralized scenario. In the decentralized case, electricity is generated to a lesser extent in cogeneration.

In the case of heat-only plants (HOPs) the existing thermal capacities are decommissioned until 2030. In general, heat-only-plants are losing competition with CHPs as they can profit only from heat sales, whereas plants operating in high efficient cogeneration can generate profit from both: electricity and heat sales. New capacity installations of heat-only technologies consist mainly of large solar thermal plants, this is especially true for the centralized High-RES scenario (cf. Fig. 12.4).

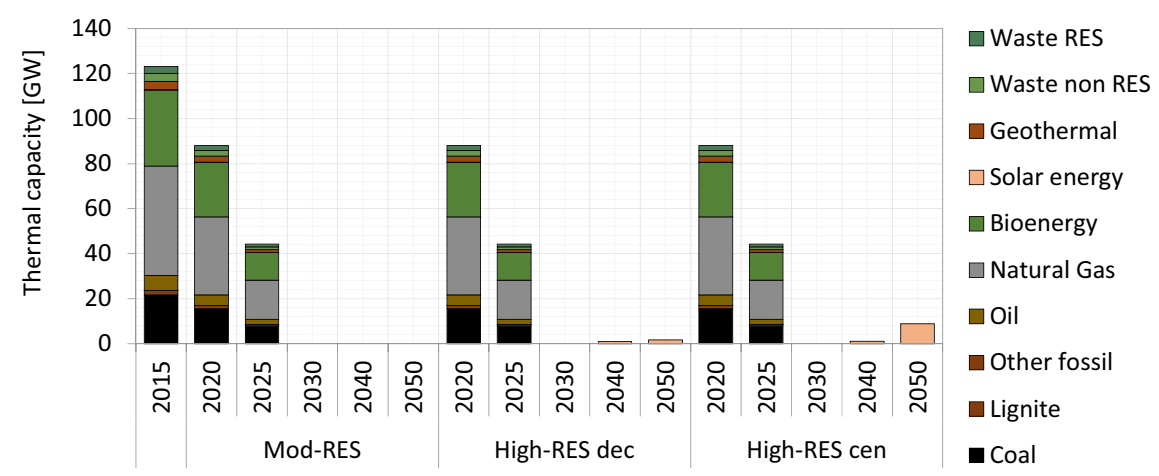

Fig. 12.4 Overall thermal capacity of heat-only plants (HOPs) in the REFLEX scenarios across all modeled countries (Source Data according to TIMES-Heat-EU model results) 
PtH technologies in TIMES-Heat-EU include electric boilers and large-scale heat pumps. Their operational pattern is different. Both PtH types are consuming electricity purchased on the wholesale electricity market. Heat pumps are assumed to operate constantly within seasons and do not actively react to the changes of the electricity price. They are more capital intensive but have higher efficiencies (the minimum value of COP is set to 3 ). In contrary, electric heaters serve as peak load units that actively respond to electricity price variations by generating heat that can be stored.

Figure 12.5 presents the installed thermal capacities of $\mathrm{PtH}$. The greatest capacity expansion, mainly electric heaters, can be observed in the High-RES centralized scenario, in which electricity price variations are higher compared to the other scenarios (there are many time-slices with low electricity price). In the centralized scenario lower incentives for DSM actions are assumed in the eLOAD model (cf. Chapters 6 and 7), that is used to generate hourly electricity demand profiles (cf. Chapter 3).

The TIMES-Heat-EU results for power-to-heat have to be interpreted differently than those of ELTRAMOD as both models represent different PtH modeling approaches: TIMES-Heat-EU is focused on the district heating sector and largescale $\mathrm{PtH}$ technologies. ELTRAMOD focuses more on small scale PtH technologies in residential and tertiary individual heating systems.

In TIMES-Heat-EU, thermal energy storages (TES) allow for short-term and seasonal storage, helping to balance heat demand and supply. Each scenario assumes the same relative split of annual district heating demand into individual time-slices (based on the outdoor temperature data). However, in absolute values, the district heating demand differs in time-slices due to the differences in annual district heating demands (which is the highest in High-RES centralized and the lowest in the decentralized scenario). It can be distinguished between three kinds of thermal energy storage systems, i.e., sensible thermal energy storage (STES), latent heat storage by phase-changing materials (PCM), and thermal-chemical storage (TCS). TIMESHeat-EU considers only sensible thermal energy storage, as phase-changing materials and thermal-chemical storage are still at a research and development stage and

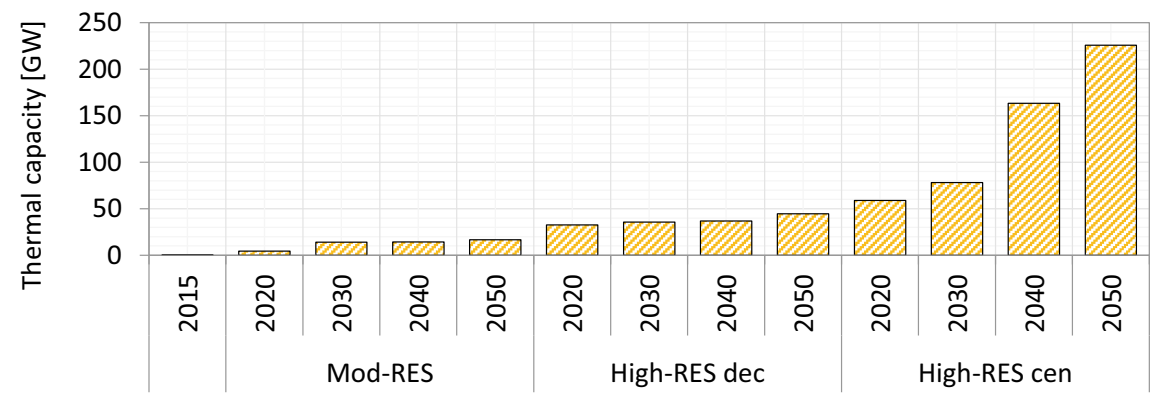

Fig. 12.5 Overall heat generation capacity of power-to-heat technologies in the REFLEX scenarios across all modeled countries (Source Data according to TIMES-Heat-EU model results) 
therefore require high investments (the advantage lies in higher storage capacity). More specifically, water tanks are selected for short-term storages, whereas borehole thermal energy storages are assumed for the seasonal storages. Figure 12.6 presents the overall amount of heat that flows out of thermal energy storages in the different REFLEX scenarios. The highest flows from inter-seasonal storages can be observed in the High-RES centralized scenario because district heating demand varies most (in absolute values) between seasons in this scenario. Short-term storages depend on the variations of DH demand between time-slices as well as on the changes in electricity prices, which influence the operation of $\mathrm{PtH}$ technologies.

Seasonal storages are employed mainly by large solar thermal plants and electric heaters. In some time-slices, in particular during summer time, RES electricity is still curtailed to some extent. This curtailed electricity could have been used by PtH technologies and stored in thermal energy storages, if sufficient capacities of $\mathrm{PtH}$ and TES had been available. However, decisions in terms of investments into new capacities are results of the economic optimization. Results show that only limited, economically viable investment in TES and PtH are made for which the costs are outweighed with the profits from the sales of district heat at a later date.

TIMES-Heat-EU calculates the weighted average annual district heating generation costs (WA-DH generation costs). In a first step, the unit district heating generation costs are calculated for each heat generation technology. These costs include fuel, fix and variable operation and maintenance costs, annualized investments as well as costs of $\mathrm{CO}_{2}$ emission allowances. In a second step, the total costs are divided by the amount of heat produced to calculate unit costs of heat generation by the given technology. This calculation is straightforward in case of heat-only-plants. In case of CHPs, the total costs are split into two parts and assigned to power and heat generated. Finally, the unit generation costs are weighed by heat production to deliver weighted average annual district heating generation costs. The development of district heating costs for selected countries (with the highest DH demand) and EU-27 + UK average is presented in Fig. 12.7. The average district heating generation costs are, in general,

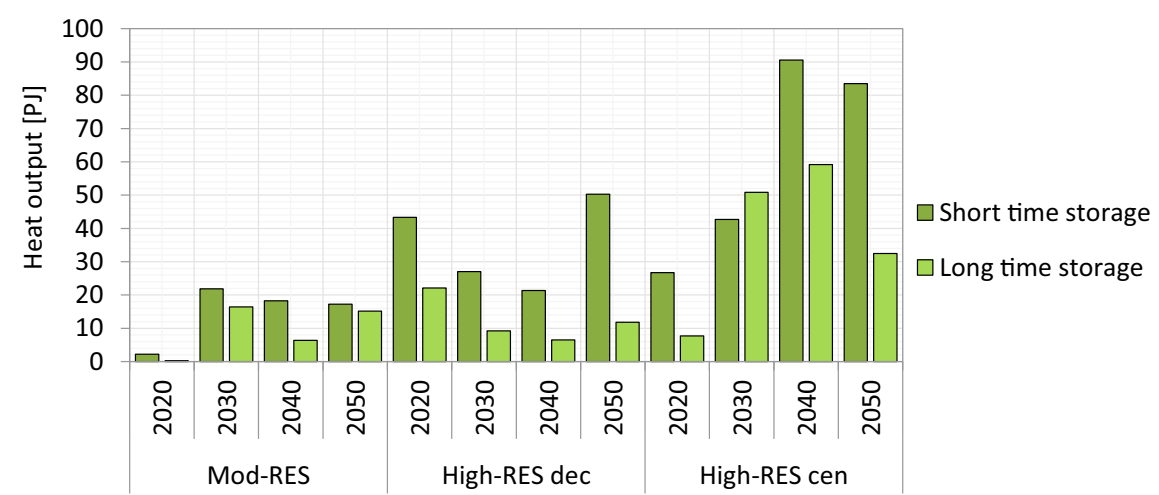

Fig. 12.6 Heat flow out of thermal energy storage in the REFLEX scenarios across all modeled countries (Source Data according to TIMES-Heat-EU model results) 


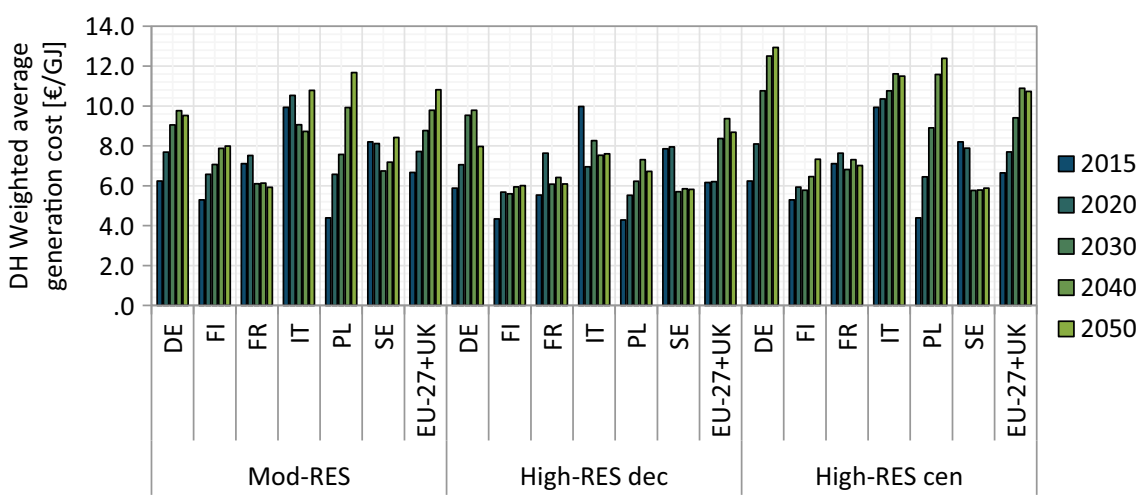

Fig. 12.7 Average district heating generation costs in the REFLEX scenarios for selected countries (Source Data according to TIMES-Heat-EU model results)

lower than the reported overall district heating price for the end-users (usually local DH operators are adding distribution and other fees, cf. Euroheat and Power 2017).

The weighted average annual district heating generation costs are increasing compared to the base-year in most of the EU-27 member states and the United Kingdom. This is mainly due to: (i) investments in new capacities, (ii) rising prices of $\mathrm{CO}_{2}$ emission allowances, and (iii) higher operational costs. Regarding (i), it should be mentioned, that investments for units that already exist in 2015 are considered in TIMES-Heat-EU as sunk costs. In the future the existing heat-only plants are replaced with CHP plants. This also has an impact as CHPs total costs are only partly assigned to heat. In reference to (ii), the weighted average annual district heating generation costs depend on the carbon intensity of the district heating generation mix. This in turn, depends on the potentials of the renewable resources and their exploitation. For instance, in the High-RES centralized scenario the bioenergy potential is fully exploited due to high district heat demand and therefore more gas-fired units have to be utilized, what is not the case in High-RES decentralized scenario. Finally, with regard to (iii), also the operational costs including mainly fuel costs have an impact on WA-DH generation costs.

As presented in Fig. 12.8, in all scenarios there are fuel and technology switches toward bioenergy (mainly biomass) and natural gas as well as toward heat production in cogeneration. Clearly, bioenergy-based CHP units are replacing existing solid fuelfired heat-only-plants and CHPs. Natural gas units are utilized in countries with low bioenergy potentials.

Figure 12.9 presents the amount of electricity produced in cogeneration for the REFLEX scenarios. As mentioned before, in case of the Mod-RES and High-RES centralized scenario the constraint to maintain about $12 \%$ of the total electricity production by CHP plants is assumed, which is not the case in the High-RES decentralized scenario. Thus, the highest electricity production occurs in the High-RES centralized scenario. In the High-RES decentralized case, the amount of electricity 


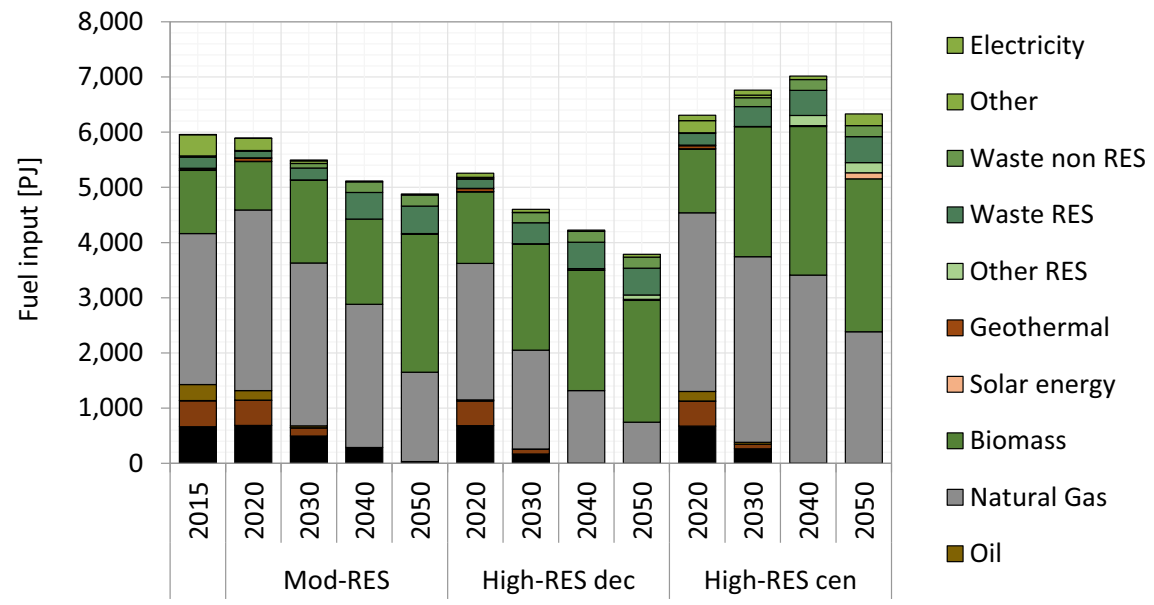

Fig. 12.8 Fuel input for DH generation in the REFLEX scenarios across all modeled countries (Source Data according to TIMES-Heat-EU model results)

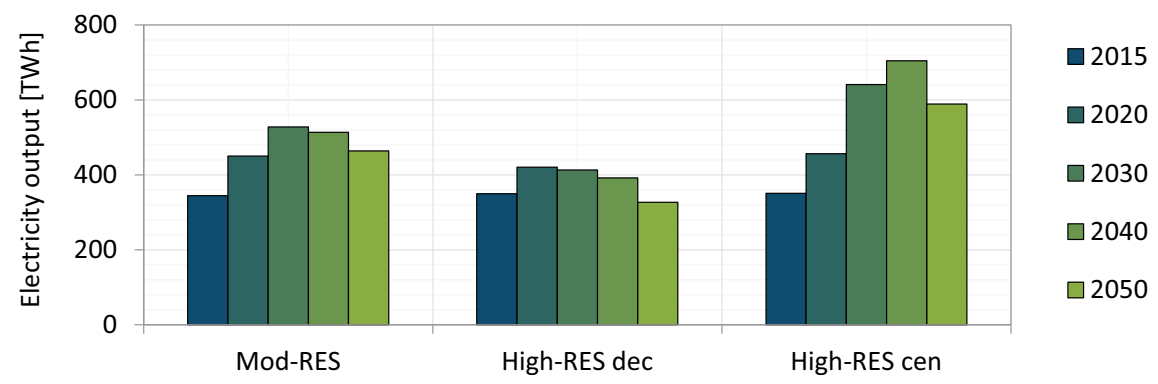

Fig. 12.9 Electricity generation of CHPs in the REFLEX scenarios across all modeled countries (Source Data according to TIMES-Heat-EU model results)

produced is associated with the DH demand and is limited by the annual efficiency requirement of cogeneration units.

\subsection{2 $\mathrm{CO}_{2}$ Emissions in the Heating Sector}

The switch in the district heating generation mix toward renewables and cogeneration results in decreasing $\mathrm{CO}_{2}$ emissions in all scenarios as depicted in Fig. 12.10.

Since the total amount of energy produced (both heat and electricity) is the highest in the High-RES centralized scenario, the corresponding $\mathrm{CO}_{2}$ emissions are also the highest in this scenario. However, as compared to the Mod-RES scenario with much lower energy (district heating and electricity) demand, the $\mathrm{CO}_{2}$ emission factor per 


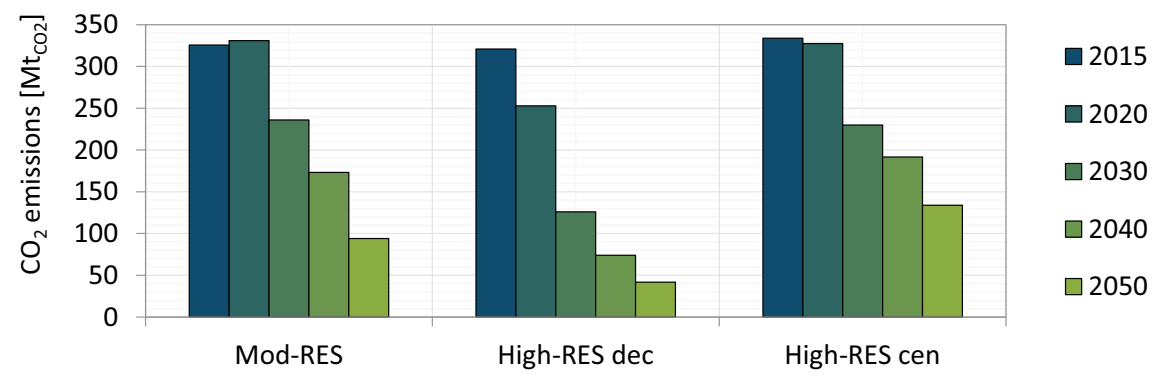

Fig. 12.10 $\mathrm{CO}_{2}$ emissions from district heating generation in the REFLEX scenarios across all modeled countries (Source Data according to TIMES-Heat-EU model results)

total energy output in 2050 in the High-RES centralized scenario is only slightly higher, as presented in Table 12.1. The reason for this is that in High-RES centralized scenario all $\mathrm{CO}_{2}$ neutral fuels (e.g., bioenergy) are used up to their supply limits, what implies the necessity to use some fossil fuels. This explains why in the HighRES decentralized scenario this emission factor is the lowest (cf. fuel input structure in Fig. 12.8). Table 12.1 summarizes the results of TIMES-Heat-EU. Specific $\mathrm{CO}_{2}$ emissions in the Mod-RES scenario are higher than in High-RES decentralized because more natural gas is used in this scenario, i.e., 33 and $20 \%$, respectively. Both scenarios have similar district heating demands, but more electricity needs to be generated in the Mod-RES scenario, due to the constraint enforcing a $12 \%$ share of CHP plants in electricity generation.

\subsubsection{Sensitivity Analysis}

One of the most important parameters influencing the results is the bioenergy supply (biomass and biogas). The available bioenergy potential has been estimated based on (Elbersen et al. 2012; Ruiz et al. 2015) and it was assumed to be 10\% higher in 2050 as compared to 2015 . Bioenergy consumption increases in every scenario, reaching the limit (available potential) in the High-RES centralized scenario. A sensitivity analysis was carried out, in which the bioenergy potential in 2050 was modified in a range from $-100 \%$ to $+80 \%$. Therefore, in 2050 , according to the former the bioenergy potential was equal to zero, while for the latter it was increased by $80 \%$ (which in absolute terms gave a number about four times higher than total bioenergy consumption in 2015). Potentials available in intermediate years were interpolated linearly between 2015 and 2050 .

The following discussion on the impact of bioenergy does not consider results of the Mod-RES scenario, as the High-RES decentralized and centralized scenario represent two extreme cases in terms of electricity and district heating demand. Figure 12.11 presents renewable energy share (mainly bioenergy but also other RES) in primary energy consumption in the DH generation sector as function of bioenergy 


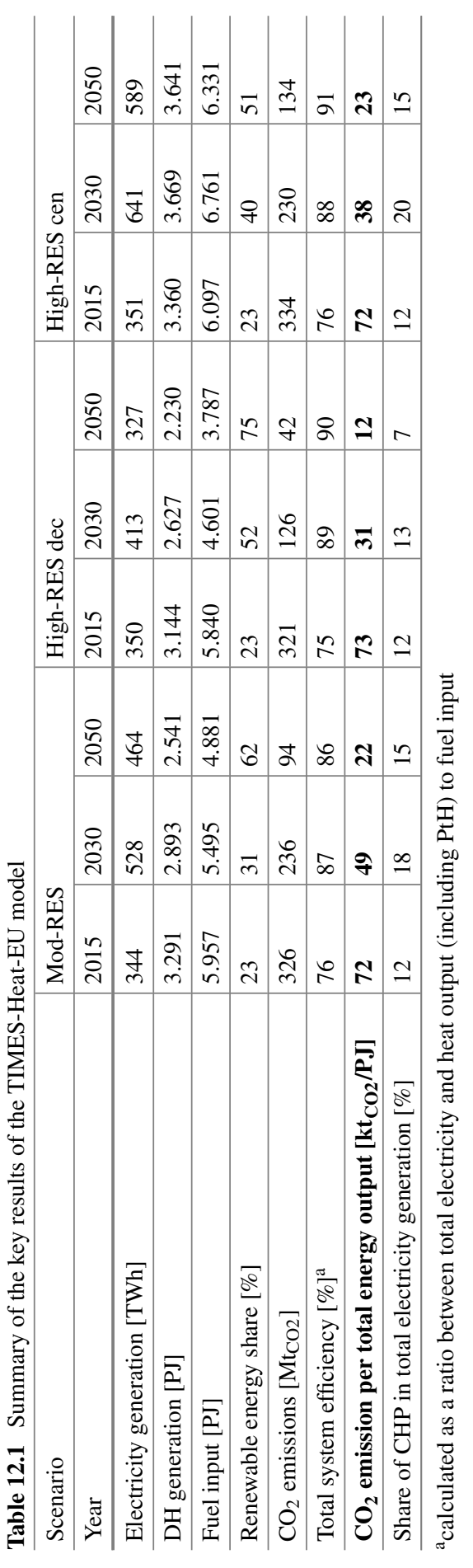




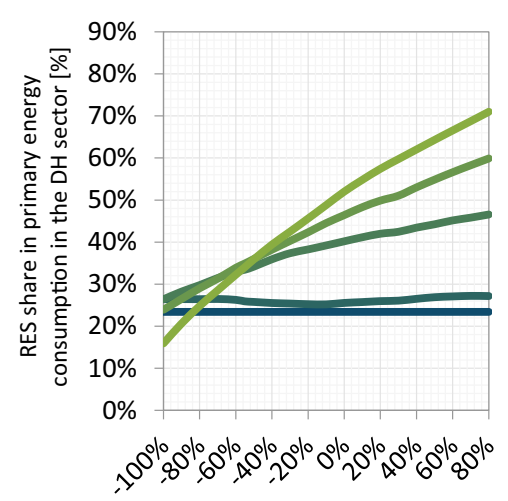

Bioenergy potential in 2050 rel. to 2015

High-RES centralized

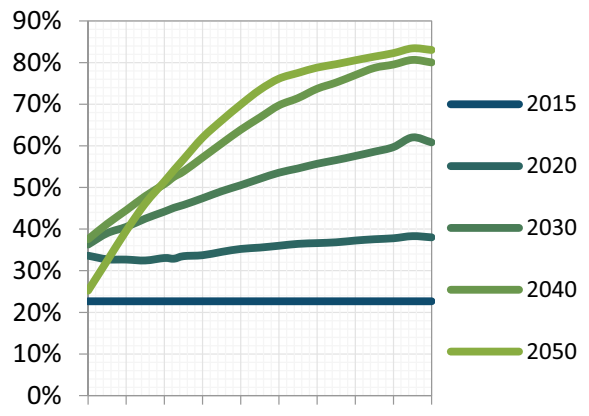

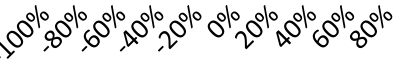

Bioenergy potential in 2050 rel. to 2015

High-RES decentralized

Fig. 12.11 Share of renewable energy in primary energy consumption in the district heating generation sector as function of bioenergy potentials in the High-RES centralized (left) and High-RES decentralized scenario (right) (Source Data according to own calculations)

potentials. Note, that in the future years it would be much easier to achieve greater RES shares in the primary energy consumption (PEC) in the High-RES decentralized scenario. This is because the overall PEC is much lower in the district heat sector in this scenario due to lower DH demand (cf. Fig. 12.2). In both scenarios the increase of bioenergy potentials leads to higher RES shares. However, in the High-RES decentralized scenario the curves flatten more in the range from 20 to + $80 \%$, indicating that greater availability of bioenergy is not influencing the results as strong as in the centralized scenario. This has two reasons. Firstly, the RES share is already very high in the baseline situation (ca. 70 and $76 \%$ in 2040 and 2050, respectively). Secondly, some peak load capacities exist (e.g., gas-fired or electric boilers) which are not viable or even sometimes technically impossible to be replaced by RES-based technologies.

The main insight of this sensitivity analysis is that if the EU member states are following the pathway described in the High-RES decentralized scenario, then the existing bioenergy potential is sufficient to fulfill the future needs for the district heating generation sector. In contrary, in case of the High-RES centralized scenario, which foresee the growth of district heating demand, the current biomass potential limits the growth and new bioenergy supply sources are required to increase the RES share.

\subsection{Conclusion}

The future district heating demand varies according to the considered REFLEX scenarios. The district heating demand is the lowest in High-RES decentralized 
and the highest in the High-RES centralized scenario. In case of the High-RES centralized scenario, the increased district heating demand has to be associated with developments of new district heating systems.

The presented results show that in the future existing heat only plants are being replaced by CHP plants. Bioenergy (mainly biomass) based CHP capacities are increasing (most significantly in the High-RES centralized scenario). This increase, however, can be constrained by the limited biomass potential. Biomass can play an important role in substituting fossil fuels in district heating generation, in particular in the EU member states where the district heating networks are already well developed. Therefore, the transition toward higher use of bioenergy (mainly biomass) requires sustainable organizational (logistic) solutions that minimize energy and $\mathrm{CO}_{2}$ emissions embedded in processing and transportation. Natural gas is still used to some extent. These results are in line with the outcomes of the "high efficiency" scenario presented in (Cogen Europe 2011) in which RES (mainly bioenergy) constitute two third in primary energy consumption in 2050 , and one third is provided by natural gas. Seasonal heat storages and short-term heat storages help to smooth generation profiles and increase the heat production in summer time. Power-to-heat technologies in the TIMES-Heat-EU model include large-scale heat pumps and electric boilers. The former operate more constantly within seasons, whereas the latter actively respond to electricity price variations and generate district heating that can be stored. The use of PtH technologies helps to manage RES electricity surpluses that otherwise would be curtailed.

With decreasing district heating demand on the one hand and with a simultaneous increase in electricity demand on the other-as in case of High-RES decentralized scenario-it is impossible to maintain the current relative share of electricity produced in cogeneration while meeting the cogeneration efficiency requirement. In fact, in this scenario this share decreases from the current 12 to $7 \%$ in 2050 . In general, district heating costs are increasing in future years. This is mainly due to the investments in new capacities, rising prices of $\mathrm{CO}_{2}$ emission allowances, and increasing fuel prices. Therefore, it is necessary to maintain the existing or newly implemented policy measures that will guarantee necessary profits for generators and keep the district heating end-user prices at competitive levels (in particular in member states where cogeneration plays a significant role). Only then, it will be possible to have an increase in district heating demand as shown in the High-RES centralized scenario. With the development of low-energy buildings, district heating networks should be expanded in regions where sufficient spatial heat density exist, in order to maintain the current district heating demand. Otherwise with decreasing district heating demand, as e.g., in case of the Mod-RES and High-RES decentralized scenario, CHPs are exposed to lower district heating and electricity sales, what leads to less favorable economic conditions for investors. 


\section{References}

Capros P, De Vita A, Tasios N, Siskos P, Kannavou M, Petropoulos A, Evangelopoulou S, Zampara M, Papadopoulos D, Paroussos L, Fragiadakis K, Tsani S, Fragkos P, Kouvaritakis N, HöglundIsaksson L, Winiwarter W, Purohit P, Gomez-Sanabria A, Frank S, Forsell N, Gusti M, Havlík P, Oberstei M, Witzke HP, Kesting M (2016) EU reference scenario 2016-Energy, transport and GHG emissions-trends to 2050. European Commission. Brussels

COGEN Europe (2011) The European association for the promotion of cogeneration-cogeneration 2050 the role of cogeneration in a European decarbonised energy system (COGEN Europe report)

Connolly J, Lund H, Mathiesen BV, Werner S, Möller B, Persson U, Boermans T, Trier D, Østergaard PA, Nielsen S (2014) Heat roadmap Europe: combining district heating with heat savings to decarbonise the EU energy system. Energy Policy 65:475-489. https://doi.org/10.1016/j.enpol. 2013

Directive 2012/27/EU of the European Parliament and of the Council of 25 October 2012 on energy efficiency, amending Directives 2009/125/EC and 2010/30/EU and repealing Directives 2004/8/EC and 2006/32/EC. https://eur-lex.europa.eu/eli/dir/2012/27/oj (Accessed 05 January 2017)

Elbersen BS, Staritsky IG, Hengeveld GM, Schelhaas MJ, Naeff HSD, Böttcher H (2012) Atlas of EU biomass potentials: spatially detailed and quantified overview of EU biomass potential taking into account the main criteria determining biomass availability from different sources. Wageningen

EUROSTAT (2017a) Combined Heat and Power (CHP) data 2005-2015. http://ec.europa.eu/eur ostat/documents/38154/4956229/CHPdata2005-2015.xlsx. (Accessed 28 February 2017)

EUROSTAT (2017b) Capacity data according to type of generation for 2015 expressed in MW. http://ec.europa.eu/eurostat/documents/38154/4956229/CHP-data-capacity-generation2015.xlsx. (Accessed 28 February 2017)

EUROSTAT (2017c) Eurostat database. https://ec.europa.eu/eurostat/data/database. (Accessed 02 March 2017)

European Comission (2016) An EU Strategy on Heating and Cooling. Communication from the Commision to the European Parliament, the Council, the European Economic and Social Committee and the Committee of the Regions, COM (2016/51) 24 final, Brussels

Euroheat \& Power (2017) Country by Country. https://www.euroheat.org/publications/country-cou ntry-2015/ (Accessed 15 January 2018)

Loulou R (2008) ETSAP-TIAM: The TIMES integrated assessment model. Part II: Mathematical formulation. Computational Management Science 5(1-2):41-66. https://doi.org/10.1007/ s10287-007-0045-0

Lund H, Werner S, Wiltshire R, Svendsen S, Thorsen JE, Hvelplund F, Mathiesen BV (2014) 4th Generation District Heating (4GDH): Integration smart thermal grids into future sustainable energy systems. Energy 68:1-11. https://doi.org/10.1016/j.energy.2014.02.089

Moya JA (2013) Impact of support schemes and barriers in Europe on the evolution of cogeneration. Energy Policy 60:345-355. https://doi.org/10.1016/j.enpol.2013.05.048

Möller B, Wiechers E, Persson U, Grundahl L, Connolly D (2018) Heat Roadmap Europe: Identifying local heat demand and supply areas with a European thermal atlas. Energy 158:281-292. https://doi.org/10.1016/j.energy.2018.06.025

Ruiz et al. (2015) The JRC-EU-TIMES model. Bioenergy potentials for EU and neighbouring countries. Brussels

World Energy Council (2016) World Energy Resources, Bioenergy

Wyrwa A, Chen Y (2017) Mapping urban heat demand with the use of GIS-based tools. Energies 10:1-15. https://doi.org/10.3390/en10050720 
Open Access This chapter is licensed under the terms of the Creative Commons Attribution 4.0 International License (http://creativecommons.org/licenses/by/4.0/), which permits use, sharing, adaptation, distribution and reproduction in any medium or format, as long as you give appropriate credit to the original author(s) and the source, provide a link to the Creative Commons license and indicate if changes were made.

The images or other third party material in this chapter are included in the chapter's Creative Commons license, unless indicated otherwise in a credit line to the material. If material is not included in the chapter's Creative Commons license and your intended use is not permitted by statutory regulation or exceeds the permitted use, you will need to obtain permission directly from the copyright holder.

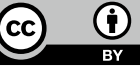

